\title{
Review
}

\section{Mitochondrial outer membrane permeabilization during apoptosis: the innocent bystander scenario}

\author{
JE Chipuk ${ }^{1,2}$, L Bouchier-Hayes ${ }^{1,2}$ and DR Green ${ }^{\star, 1}$ \\ 1 Department of Immunology, St Jude Children's Research Hospital, $332 \mathrm{~N}$. \\ Lauderdale Street, Memphis, TN, USA \\ 2 These authors contributed equally to this work. \\ * Corresponding author: DR Green, Department of Immunology, St Jude \\ Children's Research Hospital, 332 N. Lauderdale Street, Memphis, TN 38105 , \\ USA. Tel: + 1901495 4865; Fax: + 19014955766. \\ E-mail: douglas.green@stjude.org
}

Received 08.3.06; revised 11.4.06; accepted 12.4.06; published online 19.5.06 Edited by $\mathrm{C}$ Borner

\begin{abstract}
Mitochondrial outer membrane permeabilization (MOMP) is considered the 'point of no return' as this event is responsible for engaging the apoptotic cascade in numerous cell death pathways. MOMP is directly governed by a subset of the BCL2 family of proapoptotic proteins, which induce disruptions in the outer mitochondrial membrane (OMM) and subsequent release of death-promoting proteins like cytochrome $c$. The proposal here is centered on our hypothesis that MOMP is dictated by an interaction between the cytosol and the OMM, and although proteins of the OMM may be important in the process, the 'decision' to undergo apoptosis originates within the cytosol with no participation (in terms of yes, no and when) by mitochondria.

Cell Death and Differentiation (2006) 13, 1396-1402.

doi:10.1038/sj.cdd.4401963; published online 19 May 2006

Keywords: apoptosis; mitochondria; $\mathrm{BCL}-2$ proteins; $\mathrm{BH} 3-$ only proteins; MOMP; membrane

Abbreviations: APAF-1, apoptotic protease-activating factor-1; CICD, caspase-independent cell death; DRP-1, dynamin-related protein 1; IMM, inner mitochondrial membrane; MOMP, mitochondrial outer membrane permeabilization; $\mathrm{mPT}$, mitochondrial permeability transition; OMM, outer mitochondrial membrane; OXPHOS, oxidative phosphorylation; PBR, peripheral benzodiazepine receptor; ROS, reactive oxygen species; VDAC, voltagedependent anion channel
\end{abstract}

\section{Apoptosis and Caspase-Independent Cell Death: Where MOMP Happens}

Apoptotic stimulation occurs through distinct signaling cascades. ${ }^{1,2}$ The intrinsic (or mitochondrial) pathway integrates signals generated by a variety of stressors, including DNA damage, cytoskeletal damage, endoplasmic reticulum stress, loss of adhesion, growth factor withdrawal, macro- molecular synthesis inhibition and others. The characteristics of apoptosis (e.g., DNA laddering and chromatin condensation, loss of plasma membrane asymmetry and blebbing) are dependent on the activation of cysteine proteases (the caspases) that cleave numerous specific cellular substrates. The activation of caspases in the mitochondrial pathway requires mitochondrial outer membrane permeabilization (MOMP), an event that is considered to be the 'point of no return' during apoptosis as it results in the diffusion to the cytosol of numerous proteins that normally reside in the space between the outer (OMM) and inner (IMM) mitochondrial membranes (Figure 1a). ${ }^{3}$ Among these is cytochrome $c$, which serves as a cofactor for apoptotic protease-activating factor-1 (APAF-1) to trigger the formation of the apoptosome and subsequent activation of the initiator and executioner caspases, normally caspase-9 and -3, respectively.

In order for a mitochondrion to undergo MOMP, a coordinated effort between numerous BCL-2 proteins (discussed below) must be engaged to allow for permeabilization of the OMM (Figure 1b). This permeabilization is likely achieved by the formation of membrane-spanning pores through which the intermembrane space proteins are released. Once MOMP has occurred, the cytosolic machinery responds by activating caspases, or if this pathway is inhibited, a caspase-independent cell death (CICD) process ensures cellular demise. This process may utilize less tractable mechanisms, such as ROS (reactive oxygen species), loss of mitochondrial function or released mitochondrial intermembrane space proteins such as apoptosisinducing factor or endonuclease $\mathrm{G}$ to catalyze death. ${ }^{4}$ In both situations, caspase-dependent and -independent cell death, MOMP occurs. This disrupts mitochondrial function and, even in the absence of caspase activation, energy production eventually wanes and the cell is left to die. ${ }^{5}$

\section{The BCL-2 Family of Proteins: Sensors for Life and Death}

Members of the BCL-2 protein family are distinguished by the presence of up to four different BCL-2 homology domains (designated $\mathrm{BH} 1-4) .{ }^{6}$ Generally speaking, those that contain all four domains (BCL-2, BCL-xL and MCL-1) are antiapoptotic, whereas those that contain less are proapoptotic (Figure 2). The proapoptotic group can be further divided into two groups, multidomains or $\mathrm{BH} 123$ members such as $\mathrm{BAX}$ and BAK, and BH3-only proteins, including BID, BIM and PUMA, among others. The multidomain proapoptotic BCL-2 proteins, BAX and BAK, are constitutively expressed and only induce MOMP following apoptotic stimuli, suggesting that they are inactive in nonapoptotic cells. ${ }^{7,8}$ Activation by certain $\mathrm{BH} 3-$ only proteins is required for $\mathrm{BAX}$ or $\mathrm{BAK}$ to 
a

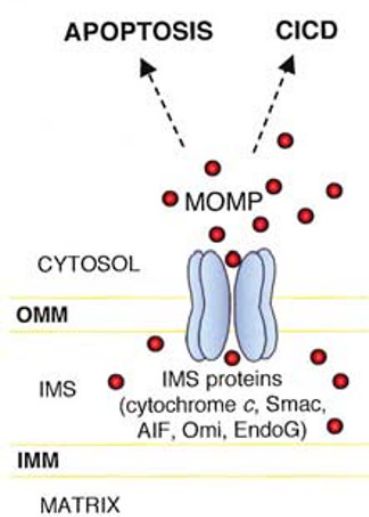

b

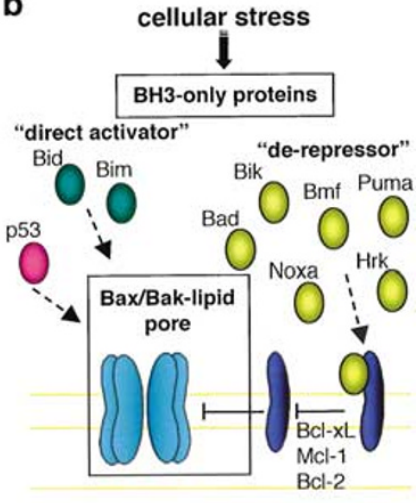

a

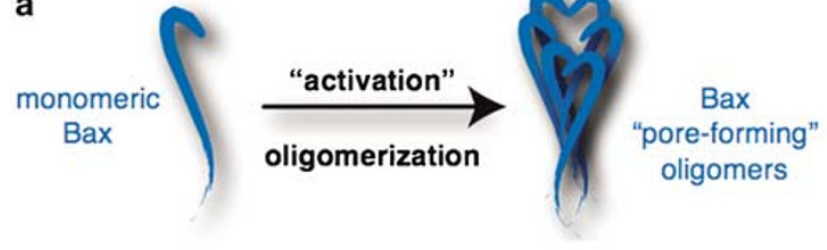

b

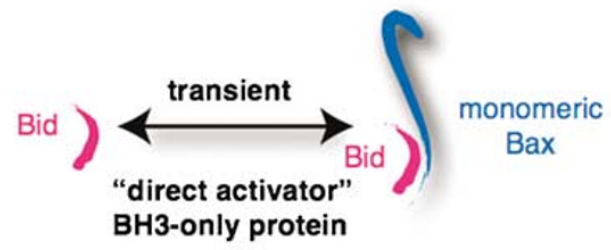

c
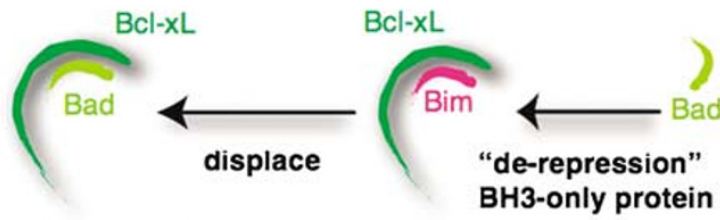

liberated
"direct activator") Bim

Figure 3 Two mechanisms of proapoptotic multidomain activation by BH3-only proteins. (a) Central to MOMP is the activation and oligomerization of BAX or BAK. These proteins, once activated by a $\mathrm{BH} 3-$ only protein, are what create pores in the OMM that permit the release of intramembrane proteins to the cytosol. (b) Direct activator BH3-only proteins, for example, BIM and BID, can induce the oligomerization and activation of BAX or BAK in the absence of other proteins. Through a transient interaction with $\mathrm{BAX}$ or BAK, the direct activator $\mathrm{BH} 3$-only proteins (BID is shown in this example), or peptides derived from the $\mathrm{BH} 3$ region, induce MOMP and cytochrome $c$ release. (c) A subset of $\mathrm{BH} 3-$ only proteins, the de-repressors, cannot induce the activation of BAX or BAK alone. In this scenario, a direct activator BH3-only protein is sequestered by an antiapoptotic BCL-2 protein. Following stress, a de-repressor BH3-only protein is induced, either by transcriptional upregulation or post-translational modification, and this protein then binds to an antiapoptotic $\mathrm{BCL}-2$ protein promoting the release of a sequestered, direct activator $\mathrm{BH} 3$-only protein. In this example, BIM is sequestered by $B C L-x L$ and the induction of $B A D$ allows for the release of $B I M$ to engage MOMP

\section{Bid, Bad, Bim, Bmt,} BNip3/Nix, Puma, Noxa

Figure 2 The BCL-2 family of proteins. The BCL-2 family of proteins is divided into antiapoptotic and proapoptotic members. The antiapoptotic members include BCL-2, BCL-xL, A1, MCL-1 and BCL-w and contain four BCL-2 homology domains (designated $\mathrm{BH} 1-4$ ). The proapoptotic multidomains (BAX, BAK and $\mathrm{BOK}$ ) contain $\mathrm{BH} 1-3$ domains. The $\mathrm{BH} 3-0$ ly proteins are structurally diverse and contain only one conserved domain, the $\mathrm{BH}$. The alpha helices of each protein are designated and the regions contained within each $\mathrm{BH}$ domain are illustrated by bold lines under each protein. The hydrophobic carboxyl-terminal transmembrane domain (TM) of each protein is based on in silico predictions and/ or structural data and is not necessarily present in each member

oligomerize and insert stably into the OMM, an important prerequisite for MOMP (unlike cytosolic BAX, BAK is constitutively mitochondrial; but like BAX, inserts into the membrane only upon activation). Korsmeyer and colleagues demonstrated that cells from mice lacking both bax and bak are resistant to a wide range of proapoptotic insults underscoring the importance of these proteins in the mitochondrial pathway. ${ }^{9}$ This is also highlighted by recent studies in growth factor-deprived bax/bak double-knockout cells where survival is maintained by marked autophagy owing to the absence of MOMP. ${ }^{10}$ This suggests that when permeabilization is inhibited, cells respond by maintaining a minimal level of survival to be rescued in the event of growth factor or nutrient re-addition. Thus, in the absence of multidomains, and therefore MOMP, the default cellular program is to sustain viability.

In order to induce death, proapoptotic multidomain proteins must be activated by the BH3-only proteins (Figure $3 \mathrm{a}$ ). A hypothesis has recently emerged that members of the $\mathrm{BH} 3-$ only family of proteins can be divided into two distinct groups: 'direct activators' that directly activate BAX or BAK (Figure $3 b$ ), and 'de-repressors' (or 'sensitizers') that allow BAX or BAK to be activated by sequestering the antiapoptotic proteins such as BCL-xL or MCL-1 and allowing for the subsequent release of previously inhibited direct activators (Figure $3 \mathrm{C}$ ). ${ }^{7,11}$ Evidence suggests that the $\mathrm{BH} 3$-only proteins, BID and BIM, act by associating with BAX and BAK, but this seems to be transient as it is not detectable in the absence of detergent. Yet, the antiapoptotic proteins, BCL-2, MCL-1 and $B C L-x L$, inhibit this interaction by binding to BID and BIM. The other members of the BH3-only family (e.g., Noxa, BMF, HRK, $B A D$ and $B I K)$ are unable to activate directly $B A X$ and $B A K$, but can bind to BCL-xL, BCL-2 and/or MCL-1 to various degrees. The direct activator/de-repressor model suggests 
that the latter proteins release BID and BIM from their antiapoptotic partners enabling activation of BAX and BAK in an indirect manner. However, another interpretation of these results is that the BH3-only proteins function to antagonize antiapoptotic BCL-2 family members, rather than engage $\mathrm{BAX}$ or BAK. ${ }^{12}$ This notion explains why combinations of the $\mathrm{BH} 3$-only proteins are required to induce cell death as each demonstrates selectivity in binding prosurvival targets. It is important to note that the majority of $\mathrm{BH} 3-$ only protein literature is based on data derived by using only the $\mathrm{BH} 3$ peptide of the corresponding protein and not on a full-length, biologically relevant protein. Similar to a BH3-only protein, p53 can function to activate directly BAX, while it also has been described to bind to $B C L-x L$ and BCL-2 similar to a de-repressor BH3-only protein. ${ }^{13-15}$ Importantly, as only three direct-activator proteins have been described (BID, BIM and p53), other proteins may also have this function(s).

Thus, there seems to be a series of checks and balances in the cytosol where activation of proapoptotic multidomain proteins not only requires a direct activator $\mathrm{BH} 3$-only protein but also repression of the antiapoptotic BCL-2 family members by additional $\mathrm{BH} 3$-only proteins (perhaps also through transcriptional downregulation or enhanced protein degradation). So, what constitutes the commitment step that, once taken, will result in MOMP? Is it the activation of BAX/ $\mathrm{BAK}$ or the induction of the $\mathrm{BH}$-only protein function? The BH3-only proteins become activated in response to different stimuli specific for each member of the family, and hence their regulators serve as primary 'sensors' for cellular stress. BID is activated upon cleavage by caspase-8, granzyme B and more weakly by caspase-2 and -3 and is engaged in response to death receptor stimulation, cytotoxic T-lymphocyte killing and heat shock, respectively. ${ }^{16-21}$ BIM, on the other hand, is held inactive in the cell through binding to the dynein light chain-1 (DLC1) and may only activate multidomains upon release from the cytoskeleton. ${ }^{22}$ Other BH3-only proteins such as BAD are activated by dephosphorylation, whereas PUMA and Noxa are transcriptionally upregulated by $\mathrm{p} 53$ and other proapoptotic stimuli.. ${ }^{23,24}$ In the presence of antiapoptotic BCL-2 proteins, activation of a direct activator $\mathrm{BH} 3-$ only protein is generally not considered sufficient to induce MOMP as it will be sequestered by antiapoptotic proteins, and hence one or more of the derepressor BH3-only proteins is also required. It is therefore likely that the same stimuli that activate BID or BIM also activate collateral de-repressor $\mathrm{BH} 3-o n l y$ proteins. For example, BMF also binds to myosin motor complexes (DLC2) and thus may detect similar cytoskeletal changes as BIM. ${ }^{25}$ However, activation of $\mathrm{BH} 3-o n l y$ proteins is probably not sufficient to ensure that every cell will initiate MOMP. This is certainly the case in many human cancers where BCL-2 is overexpressed conferring resistance to chemotherapy. ${ }^{26}$ It is likely that multiple signaling cascades are required for initiating MOMP, perhaps through the combined efforts of transcriptional regulation and complex post-translational modification (cleavage, phosphorylation, etc.). Considering the complexity and irreversibility of MOMP, we suggest that unrestrained activation of $\mathrm{BAX}$ or BAK is the ultimate commitment to cell death.

\section{MOMP: (How) Are Mitochondria Really Involved?}

By definition, MOMP occurs in the OMM, but this does not afford us with an explanation of how it occurs. There are various ways in which mitochondria may regulate their own permeabilization and these originate from either the IMM or OMM.

\section{The inner membrane}

The inner membrane may either cause or control MOMP through involvement of the mitochondrial permeability transition (mPT) pore. ${ }^{27}$ The $\mathrm{mPT}$ pore is a complex composed of several different proteins including VDAC (voltage-dependent anion channel), ANT and cyclophilin D (cypD), which span the IMMs and OMMs where ANT is on the inner membrane and VDAC is on the outer membrane (Figure 4a). Opening of this pore allows for an influx of ions and other small molecules into the mitochondrial matrix causing swelling of the matrix, inducing rupture of the OMM and thus MOMP. The MPT pore has been implicated as being responsible for MOMP in certain scenarios including conditions of ER stress or ROS. It has been proposed that during ER stress-induced apoptosis, $\mathrm{Ca}^{2+}$ is released from the ER and is taken up by mitochondria resulting in cytochrome $c$ release and apoptosis. $\mathrm{Ca}^{2+}$. induced cytochrome $c$ release from mitochondria appeared to occur in the absence of BAX and BAK (although BAX and BAK may function to control $\mathrm{Ca}^{2+}$ release from ER) suggesting $\mathrm{mPT}$ pore involvement. ${ }^{28}$ However, under physiological conditions, the amount of calcium released from the ER is not sufficient to induce $\mathrm{MPT}$ in mitochondria, leading to the assumption that $\mathrm{Ca}^{2+}$-induced $\mathrm{mPT}$ occurs in those mitochondria that are proximal to the ER. If so, then MOMP should only occur in these settings in a small subset of mitochondria,
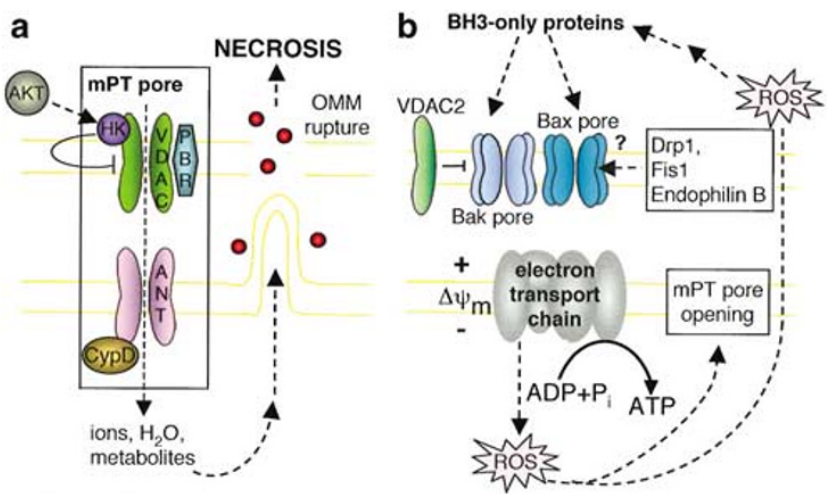

Figure 4 (a) Schematic representation of the $\mathrm{MPT}$ pore model. The hypothetical mPT pore is comprised of VDAC, ANT and a number of other proteins. Opening of the pore allows for an influx of water and ions into the matrix inducing swelling and rupture of the OMM and most likely results in necrosis. Various proteins have been suggested to regulate the $\mathrm{MPT}$ including hexokinase (HK) and the PBR. (b) Other proteins have been suggested to regulate MOMP specifically the formation of the BAX (or BAK) pore including VDAC2 and proteins that regulate mitochondrial fission and fusion. Further, mitochondrial components may independently induce MOMP including ROS produced by the electron transport chain, which may cause opening the MPT pore, but equally may induce apoptosis via activation of $\mathrm{BH} 3$-only proteins in the cytoplasm 
a prediction that is not supported by direct observations of cytochrome $c$ release ${ }^{29,30}$ (unpublished observations).

Recently, a number of genetic models have called into question the importance of $\mathrm{MPT}$ as a general inducer of MOMP. ANT seems to be dispensable as mice lacking ANT can still undergo $\mathrm{mPT}$, whereas cells that lack cypD (therefore have no $\mathrm{mPT}$ ) showed no difference in $\mathrm{Ca}^{2+}$-induced or a variety of other forms of apoptosis, although $\mathrm{Ca}^{2+}$-induced necrosis was defective. ${ }^{31-33}$ These results from the Ppif KO mice (the gene encoding cypD) suggest that $\mathrm{mPT}$ may not be required during apoptosis (in most cases at least) and does occur during ischemia and ROS-induced necrosis; however, the role and mechanism of death remains unknown. ${ }^{31}$ Furthermore, as $\mathrm{mPT}$ is highly temperature sensitive, the coordinated release of cytochrome $c$ at different temperatures argues against any sort of mPT chain reaction. ${ }^{5,29}$ Taken together, these data suggest that the mPT pore, although important for necrotic death, may not be necessary for MOMP that occurs during mitochondrial apoptosis (Figure 4a).

The inner membrane may alternatively control MOMP by regulating OXPHOS (oxidative phosphorylation), which in turn regulates the mitochondrial transmembrane potential $\left(\Delta \psi_{\mathrm{m}}\right) .^{34}$ The maintenance of $\Delta \psi_{\mathrm{m}}$ is required for a variety of mitochondrial functions including protein import, ATP production and regulation of metabolite transport. The onset of MOMP is often associated with a loss of $\Delta \psi_{\mathrm{m}}$, but does this loss of $\Delta \psi_{\mathrm{m}}$ induce MOMP or does it occur as a result of MOMP? Disruption of $\Delta \psi_{\mathrm{m}}$ caused by incomplete reduction of molecular oxygen during OXPHOS leads to ROS generation that triggers MOMP, but this may occur via an interaction of ROS with as yet unidentified cytosolic sensors. Indeed, ROS that is generated during apoptosis is often caused by caspase-dependent cleavage of a subunit of complex I of the respiratory chain and hence can be a byproduct of MOMP rather than causative. ${ }^{34,35}$ Otherwise, there is no compelling evidence that loss of $\Delta \psi_{\mathrm{m}}$ directly induces MOMP, and OXPHOS can clearly continue after MOMP since, in the absence of caspase activation, not only can $\Delta \psi_{\mathrm{m}}$ be regenerated, but the cells also can maintain ATP production. ${ }^{34-36}$

\section{The outer membrane}

Compelling evidence that the inner membrane (and indeed the matrix) is not necessary for MOMP and that MOMP only requires the OMM has been provided by Kuwana et al. ${ }^{8}$ Using a reductionist approach to dissect the requirements for MOMP, they demonstrated that unilamellar vesicles comprised of the lipids present in the mitochondrial membrane release their contents in the presence of activated BAX. The use of defined liposomes and recombinant BCL-2 family proteins here may represent 'simplified' mitochondria, suggesting that the only mitochondrial requirement for the release of intermembrane space proteins is cardiolipin, a lipid that is specific to mitochondrial membranes. As no other proteins are required to release the liposome contents, these observations favor a mechanism of MOMP where activated BAX (and/or BAK) forms a pore in the lipid membrane to allow release of cytochrome $c$. However, this simplified liposome system may not accurately reflect the complexity of the permeabilization process as it occurs in the native OMM and certain stimuli may require OMM proteins to allow for the formation of the BAX/lipid pore. In the absence of detergent, BAX requires membranes (cardiolipin-containing liposomes or mitochondria) to oligomerize and activate, and evidence suggests that $B C L-x L$ will only inhibit BAX in the presence of similar lipid membranes. ${ }^{8}$ However, the importance of cardiolipin in this process is also controversial. In yeast, cardiolipin does not seem to be required for BAX-induced death. ${ }^{37}$ Moreover, the presence or exact amount of cardiolipin in the OMM is not known and it may be present in, at best, very low levels. Immunogold staining experiments suggest that cardiolipin in the outer membrane is concentrated at the contact points between the IMM and OMM where BAX/BID are proposed to bind, and perhaps the local concentration of cardiolipin at these sites may be sufficiently high to allow binding of these proteins. ${ }^{38,39}$ Alternatively, there may be OMM proteins that concentrate cardiolipin, allowing for the insertion of activated BAX and/or BAK into the OMM to mediate MOMP.

There are two further levels of potential regulation that exist in the physiological context of an intact OMM (Figure 4b). First, proteins associated with the OMM, in addition to BCL-2 family members may directly regulate MOMP; and second, perhaps additional proteins associated with the OMM, also in addition to BCL-2 family members, participate in MOMP but do not regulate the process. For example, many of the proteins that have been described to regulate the $\mathrm{MPT}$ pore also have claims to participate additionally in MOMP. This is where a subtle difference, and perhaps, overlooked aspect of MOMP arises. Although there are numerous proteins in the $\mathrm{OMM}$, most of these are not required for BAX or BAK to permeabilize mitochondria. Outer membrane vesicles prepared from mitochondria permeabilize upon treatment with tBID similar to intact mitochondria; this must be independent of $\mathrm{mPT}$ pore function as these are devoid of mitochondrial inner membrane constituents. ${ }^{8}$ Yet, several proteins at the OMM are speculated to regulate BAX or BAK-mediated permeabilization because of a demonstrated association with the latter proteins. For example, BCL-2, BCL-xL, BAK and BAX have all been shown to bind VDAC, although it should be noted that as VDAC is the most abundant protein of the OMM, the binding may not be physiological. ${ }^{40-43}$ More specifically, Korsmeyer and colleagues suggested that VDAC2 inhibits BAK activation by maintaining BAK as a monomer in the OMM (Figure $4 b) .{ }^{44}$ While this may be the case, VDAC2 may not make the decision to activate or inactivate BAK since in this scenario it is a cytosolic signal response to cellular stress, most likely a BH3-only protein, that disrupts the VDAC2-BAK association. ${ }^{44}$

Similarly, it has been suggested that the peripheral benzodiazepine receptor (PBR) blocks MOMP. ${ }^{45,46}$ This integral membrane protein functionally interacts with the MPT pore and is a suggested inhibitor of MOMP. Yet, the requirements for cell death still do not change, both cellular stress and BH3-only proteins are necessary, as simple pharmacological inhibition or disruption of PBR activity is not sufficient for the mitochondria to broadcast a proapoptotic signal; and use of inhibitors certainly may not reflect the physiological functions of these proteins. ${ }^{46}$ Such proteins (e.g., VDAC1/2 and PBR) may associate with numerous 
BCL-2 proteins, but the signal for MOMP cannot originate from within mitochondria; the cell must generate a proapoptotic message that feeds forward (stress $\rightarrow$ cellular detection $\rightarrow$ cellular response $\rightarrow$ activation of $\mathrm{BH} 3$-only proteins $\rightarrow$ $\mathrm{BAX} / \mathrm{BAK}$ activation $\rightarrow \mathrm{MOMP}$ ) to the mitochondrial surface to regulate these interactions.

A description of such a 'feedforward' situation considers the role of AKT and hexokinase $\mathrm{I} / \mathrm{II}$ in the prevention of cytochrome $c$ release in certain survival pathways. AKT activity seems to be required to balance the requirements for glucose uptake, and subsequent metabolite transport across both the IMM and OMM by directly regulating the expression and localization of hexokinase on the OMM. ${ }^{47,48}$ Interestingly, AKT activity increased the mass of hexokinase on the surface of mitochondria, which has been demonstrated to influence dramatically VDAC channel activity. ${ }^{47}$ When cells were treated with agents that disrupted the hexokinase-mitochondria association, accelerated cytochrome $c$ release occurred only following additional proapoptotic stress. ${ }^{47}$ Furthermore, a reduction of $\mathrm{BAX}$ translocation has been reported during instances of enforced hexokinase-mitochondrial association during stress. ${ }^{47}$ Together, this indicates that simple removal of hexokinase from the OMM is not sufficient to induce MOMP as the cells still do not release cytochrome $c$ in the absence of stress, and that the signal to recruit BAX to the OMM must originate outside mitochondria regardless of hexokinase participation.

Another major class of proteins that reside in the OMM is responsible for mitochondrial dynamics: the fusion and fission proteins (Figure 4b). Mitochondrial dynamics are required for distributing mitochondria to daughter cells following mitosis and ensure that mitochondrial integrity is preserved as mitochondrial membranes divide and fuse. ${ }^{49}$ There are at least four OMM proteins that potentially participate in, or regulate MOMP: DRP-1 (a dynamin-related GTPase), endophilin B1 (a lipid transferase required for determining membrane curvature), Fis-1 (and integral OMM protein) and Fzo1/Mfn1 (a large transmembrane GTPase). ${ }^{50}$

Thus far, it has been described that BAX and BAK, upon activation, coalesce with mitochondrial scission foci that are comprised minimally of DRP-1 and mitofusin-2, and that BAX can physically interact with endophilin B1 in the OMM; yet, dominant-negative forms of DRP-1, such as GTPase-deficient DRP-1 ${ }^{\mathrm{K} 38 \mathrm{~A}}$, do not block the translocation of BAX following activation by a $\mathrm{BH} 3-$ only protein. ${ }^{51-53}$ Again, the signal responsible for promoting $\mathrm{BAX}$ translocation to the $\mathrm{OMM}$ is generated as a consequence of the particular cellular stress (i.e., the activated set of BH3-only proteins). But, what is the purpose of $\mathrm{BAX} / \mathrm{BAK}$ interacting with this class of proteins? Do these proteins simply participate as 'docking points' for BAX or BAK, or is there an active regulation of MOMP involved? Upon activation, BAX must be able to target the appropriate intracellular membrane (i.e., the OMM) in order to engage the apoptotic cascade and these proteins may serve to 'dock' BAX to the OMM. If true, this interpretation could not be extended to include BAK as it is constitutively resides in the OMM. Yet, perhaps regulators of mitochondrial dynamics (such as DRP-1 or Fis-1) have evolved to participate in MOMP by directing the action of BAX and BAK to the appropriate region of the OMM allowing for their pore-forming activity. In this scenario, the proposed interaction does not itself serve to make the cellular decision to induce MOMP, but it is still required. A reciprocal interaction has also been reported where antiapoptotic BCL-2 members promoted the remodeling of the mitochondrial network via a mitofusin-2 interaction that resulted in mitochondrial fusion and decreased sensitivity to cell death. ${ }^{54}$ In this scenario, it was shown that CED-9, the Caenorhabditis elegans BCL-2 relative, could induce mitochondrial clustering. Similar mitochondrial reorganization was also induced by enforced $\mathrm{BCL}-\mathrm{xL}$ expression, suggesting that this activity may be a conserved function of the BCL-2 family. ${ }^{54}$

Another potential aspect to this scenario relates to the specific lipid requirement for BAX (and presumably, BAK) to permeabilize an OMM. As discussed earlier, in vitro data suggest that $\mathrm{BAX}$ requires cardiolipin to oligomerize and engage pore-forming activity. ${ }^{8}$ As cardiolipin primarily localizes in the IMM, does the fusion/fission machinery also regulate BAX-mediated MOMP by creating the appropriate lipid milieu at the contact sites with DRP-1 or Fis-1? Endophilin B1, a lipid transferase, interacts with BAX and may serve to re-distribute IMM lipids to contact sites for efficient activation of BAX (and by extension, BAK). ${ }^{55,56}$ If this activity is required, then endophilin $\mathrm{B} 1$ may serve as a bona fide regulator of MOMP as its necessary function may itself be subject to mitochondrial dynamics and energetics. The issue is whether or not regulation of endophilin B1 ever helps to determine if and when MOMP will occur.

\section{The Innocent Bystander Scenario}

Given the evidence outlined here that the most likely mechanism for MOMP is the BAX/BAK-lipid pore with no further requirement for proteins in the IMM or OMM, we propose this possibility: mitochondria are essentially 'innocent bystanders' in the process of MOMP. Thus, it is a process entirely controlled by the BCL-2 family of proteins and their regulators within the cytosol. Although it is possible that proteins associated with mitochondria directly and indirectly regulate the $B C L-2$ family to induce MOMP, we suggest that it is still the activation of BAX and BAK that exclusively engages MOMP, and the control of this activation is what produces apoptosis. No other events other than opening the OMM regulate this step in apoptosis.

This is important to note because following the discovery of MOMP, a logical error occurred, as follows. Permeabilization of the OMM causes apoptosis and subsequently 'damages' mitochondria by physical disruption and eventual waning of mitochondrial function. Ergo, it is assumed that mitochondrial damage, in any form, causes apoptosis. The innocent bystander scenario suggests that MOMP is a very specific sort of mitochondrial damage, caused exclusively by BAX and BAK. Other forms of mitochondrial damage (perhaps to the outer or inner membranes, or targeted to mitochondrial DNA, etc.) will not signal apoptosis simply by virtue of the damage, but may signal other forms of cell death such as necrosis. If apoptosis does occur subsequent to these forms of damage, it is through other signaling events, such as ROS generation, that are sensed by the cytosol or nucleus to generate 
additional signals that directly activate BAX and BAK. From this point of view, mitochondrial damage is no different from other forms of damage within a cell (e.g., genotoxic stress), and does not represent an alternative to BAX/BAK-controlled MOMP. An elegant study that examined the release of cytochrome $c$ following partial mitochondrial damage supports this model. ${ }^{57}$ In this system, mitochondria were labeled with a photosensitizer (Chloromethyl-X-Rosamine) and then a small subset of mitochondria was photoirradiated. Within the cell, the entire mitochondrial population released cytochrome $c$ in a rapid and coordinated manner, suggesting that a signal (probably ROS) between the irradiated and nonirradiated mitochondria was generated; this signaling also occurred in the absence of waves (one mitochondrion communicating with its neighbor), suggesting a cytosolic sensor leading to coordinated BAX/BAK activation throughout the cell $(\mathrm{a} \mathrm{BH3-}$ only proteins) was emanated to the entire mitochondrial population.

The innocent bystander hypothesis discussed here should not be confused with an alternative viewpoint that mitochondria simply serve to amplify the apoptotic signal downstream of caspase activation. ${ }^{58}$ Despite recent evidence from the caspase-3 and -7 double-knockout mice, which suggests that caspases may act to induce BAX translocation and cytochrome $c$ release, there is a sustained and clear literature that supports the requirement for cytochrome $c$ and APAF-1 in the activation of caspases. ${ }^{59,60}$ Furthermore, numerous rigorous studies have demonstrated that cytochrome $c$ release from mitochondria is complete and independent of caspase activation. ${ }^{29,34-36,59,61,62}$ Further studies are required to integrate the requirement for caspases in MOMP induction.

Evidence from in vitro liposome studies, single-cell kinetic analysis and various genetic models has failed to provide overwhelming evidence that the OMM or the IMM directly regulates or induces MOMP. Thus, according to our innocent bystander hypothesis, the commitment to die in this pathway, or rather the commitment step that results in induction of MOMP rests entirely with the BCL-2 family of proteins and their regulators. We do not argue that the OMM or IMM does not participate in the induction of MOMP but that, if they do, they do so in a manner that always depends on the activities of the BH3-only or multidomain BCL-2 proteins in the cytosol. More importantly, the innocent bystander scenario proposes that MOMP can, and we suggest does, occur in the absence of decision-making events (proteins, membrane changes, ROS etc.) that are intrinsic to the mitochondrial membranes.

\section{Acknowledgements}

Our work is the poorer for the loss of our dear and valuable colleague, Stan Korsmeyer, whose leadership in this field is without compare. This review celebrates his accomplishments, and how his insights and discoveries have impacted on our thinking, research and understanding of the function of the BCL-2 family in apoptosis. We are dedicated to pursuing the work that he inaugurated, and in doing so, hope in our small way to keep his wonderful scientific spirit vibrant. This is for Stan. We only fervently wish we could discuss these ideas with him.

\section{References}

1. Spierings D, McStay G, Saleh M, Bender C, Chipuk J, Maurer U and Green DR (2005) Connected to death: the (unexpurgated) mitochondrial pathway of apoptosis. Science 310: 66-67.

2. Danial NN and Korsmeyer SJ (2004) Cell death: critical control points. Cell 116: 205-219.

3. Von Ahsen O, Waterhouse NJ, Kuwana T, Newmeyer DD and Green DR (2000) The 'harmless' release of cytochrome c. Cell Death Differ. 7: 1192-1199.

4. Chipuk JE and Green DR (2005) Do inducers of apoptosis trigger caspaseindependent cell death? Nat. Rev. Mol. Cell. Biol. 6: 268-275.

5. Ricci JE, Waterhouse N and Green DR (2003) Mitochondrial functions during cell death, a complex (I-V) dilemma. Cell Death Differ. 10: 488-492.

6. Kuwana T and Newmeyer DD (2003) Bcl-2-family proteins and the role of mitochondria in apoptosis. Curr. Opin. Cell. Biol. 15: 691-699.

7. Letai A, Bassik MC, Walensky LD, Sorcinelli MD, Weiler S and Korsmeyer SJ (2002) Distinct BH3 domains either sensitize or activate mitochondrial apoptosis, serving as prototype cancer therapeutics. Cancer Cell. 2: 183-192.

8. Kuwana T, Mackey MR, Perkins G, Ellisman MH, Latterich M, Schneiter R, Green DR and Newmeyer DD (2002) Bid, Bax, and lipids cooperate to form supramolecular openings in the outer mitochondrial membrane. Cell 111: 331-342.

9. Wei MC, Zong WX, Cheng EH, Lindsten T, Panoutsakopoulou V, Ross AJ, Roth KA, MacGregor GR, Thompson CB and Korsmeyer SJ (2001) Proapoptotic $B A X$ and BAK: a requisite gateway to mitochondrial dysfunction and death. Science 292: 727-730.

10. Lum JJ, Bauer DE, Kong M, Harris MH, Li C, Lindsten T and Thompson CB (2005) Growth factor regulation of autophagy and cell survival in the absence of apoptosis. Cell 120: 237-248.

11. Kuwana T, Bouchier-Hayes L, Chipuk JE, Bonzon C, Sullivan BA, Green DR and Newmeyer DD (2005) BH3 domains of BH3-only proteins differentially regulate Bax-mediated mitochondrial membrane permeabilization both directly and indirectly. Mol. Cell 17: 525-535.

12. Chen L, Willis SN, Wei A, Smith BJ, Fletcher JI, Hinds MG, Colman PM, Day $\mathrm{CL}$, Adams JM and Huang DC (2005) Differential targeting of prosurvival Bcl-2 proteins by their $\mathrm{BH} 3$-only ligands allows complementary apoptotic function. Mol. Cell 17: 393-403.

13. Mihara M, Erster S, Zaika A, Petrenko O, Chittenden T, Pancoska P and Moll UM (2003) p53 has a direct apoptogenic role at the mitochondria. Mol. Cell 11: 577-590.

14. Chipuk JE, Kuwana T, Bouchier-Hayes L, Droin NM, Newmeyer DD, Schuler M and Green DR (2004) Direct activation of Bax by p53 mediates mitochondrial membrane permeabilization and apoptosis. Science 303: 1010-1014.

15. Tomita $Y$, Marchenko N, Erster S, Nemajerova A, Dehner A, Klein C, Pan H, Kessler H, Pancoska P and Moll UM (2006) WTp53 but not tumor-derived mutants bind to BCL2 via the DNA binding domain and induce mitochondrial permeabilization. J. Biol. Chem. 281: 8600-8606.

16. Luo X, Budihardjo I, Zou H, Slaughter C and Wang X (1998) Bid, a Bcl2 interacting protein, mediates cytochrome $c$ release from mitochondria in response to activation of cell surface death receptors. Cell 94: 481-490.

17. Li H, Zhu H, Xu CJ and Yuan J (1998) Cleavage of BID by caspase 8 mediates the mitochondrial damage in the Fas pathway of apoptosis. Cell 94: 491-501.

18. Bonzon C, Bouchier-Hayes L, Pagliari LJ, Green DR and Newmeyer DD (2006) Caspase-2-induced apoptosis requires bid cleavage: a physiological role for bid in heat shock-induced death. Mol. Biol. Cell. 17: 2150-2157.

19. Heibein JA, Goping IS, Barry M, Pinkoski MJ, Shore GC, Green DR and Bleackley RC (2000) Granzyme B-mediated cytochrome $c$ release is regulated by the Bcl-2 family members bid and Bax. J. Exp. Med. 192: 1391-1402.

20. Barry M, Heibein JA, Pinkoski MJ, Lee SF, Moyer RW, Green DR and Bleackley RC (2000) Granzyme B short-circuits the need for caspase 8 activity during granule-mediated cytotoxic T-lymphocyte killing by directly cleaving Bid. Mol. Cell. Biol. 20: 3781-3794.

21. Tu S, McStay GP, Boucher LM, Mak T, Beere HM and Green DR (2006) In situ trapping of activated initiator caspases reveals a role for caspase-2 in heat shock-induced apoptosis. Nat. Cell Biol. 8: 72-77.

22. Puthalakath H, Huang DC, O'Reilly LA, King SM and Strasser A (1999) The proapoptotic activity of the Bcl-2 family member Bim is regulated by interaction with the dynein motor complex. Mol. Cell 3: 287-296. 
23. Oda E, Ohki R, Murasawa $\mathrm{H}$, Nemoto J, Shibue T, Yamashita T, Tokino $\mathrm{T}$, Taniguchi T and Tanaka N (2000) Noxa, a BH3-only member of the Bcl-2 family and candidate mediator of p53-induced apoptosis. Science 288: 1053-1058.

24. Nakano K and Vousden KH (2001) PUMA, a novel proapoptotic gene, is induced by p53. Mol. Cell 7: 683-694.

25. Puthalakath H, Villunger A, O'Reilly LA, Beaumont JG, Coultas L, Cheney RE, Huang DC and Strasser A (2001) Bmf: a proapoptotic BH3-only protein regulated by interaction with the myosin $\mathrm{V}$ actin motor complex, activated by anoikis. Science 293: 1829-1832.

26. Bouchier-Hayes L, Lartigue L and Newmeyer DD (2005) Mitochondria: pharmacological manipulation of cell death. J. Clin. Invest. 115: 2640-2647.

27. Zamzami N, Larochette N and Kroemer G (2005) Mitochondrial permeability transition in apoptosis and necrosis. Cell Death Differ. 12 (Suppl 2): 1478-1480.

28. Scorrano L, Oakes SA, Opferman JT, Cheng EH, Sorcinelli MD, Pozzan T and Korsmeyer SJ (2003) BAX and BAK regulation of endoplasmic reticulum $\mathrm{Ca}^{2+}$ : a control point for apoptosis. Science 300: 135-139.

29. Goldstein JC, Waterhouse NJ, Juin P, Evan Gl and Green DR (2000) The coordinate release of cytochrome $c$ during apoptosis is rapid, complete and kinetically invariant. Nat. Cell Biol. 2: 156-162.

30. Goldstein JC, Munoz-Pinedo C, Ricci JE, Adams SR, Kelekar A, Schuler M, Tsien RY and Green DR (2005) Cytochrome $c$ is released in a single step during apoptosis. Cell Death Differ. 12: 453-462.

31. Baines CP, Kaiser RA, Purcell NH, Blair NS, Osinska H, Hambleton MA, Brunskill EW, Sayen MR, Gottlieb RA, Dorn GW, Robbins J and Molkentin JD (2005) Loss of cyclophilin D reveals a critical role for mitochondrial permeability transition in cell death. Nature 434: 658-662.

32. Nakagawa T, Shimizu S, Watanabe T, Yamaguchi O, Otsu K, Yamagata H, Inohara $\mathrm{H}$, Kubo $\mathrm{T}$ and Tsujimoto $\mathrm{Y}$ (2005) Cyclophilin D-dependent mitochondrial permeability transition regulates some necrotic but not apoptotic cell death. Nature 434: 652-658.

33. Kokoszka JE, Waymire KG, Levy SE, Sligh JE, Cai J, Jones DP, MacGregor GR and Wallace DC (2004) The ADP/ATP translocator is not essential for the mitochondrial permeability transition pore. Nature 427: 461-465.

34. Ricci JE, Gottlieb RA and Green DR (2003) Caspase-mediated loss of mitochondrial function and generation of reactive oxygen species during apoptosis. J. Cell Biol. 160: 65-75.

35. Ricci JE, Munoz-Pinedo C, Fitzgerald P, Bailly-Maitre B, Perkins GA, Yadava N, Scheffler IE, Ellisman MH and Green DR (2004) Disruption of mitochondrial function during apoptosis is mediated by caspase cleavage of the $p 75$ subunit of complex I of the electron transport chain. Cell 117: 773-786.

36. Waterhouse NJ, Goldstein JC, von Ahsen O, Schuler M, Newmeyer DD and Green DR (2001) Cytochrome $c$ maintains mitochondrial transmembrane potential and ATP generation after outer mitochondrial membrane permeabilization during the apoptotic process. J. Cell Biol. 153: 319-328.

37. Iverson SL, Enoksson M, Gogvadze V, Ott M and Orrenius S (2004) Cardiolipin is not required for Bax-mediated cytochrome $c$ release from yeast mitochondria. J. Biol. Chem. 279: 1100-1107.

38. Lutter M, Perkins GA and Wang X (2001) The pro-apoptotic Bcl-2 family member tBid localizes to mitochondrial contact sites. BMC Cell Biol. 2: 22.

39. Lutter M, Fang M, Luo X, Nishijima M, Xie X and Wang X (2000) Cardiolipin provides specificity for targeting of tBid to mitochondria. Nat. Cell Biol. 2: 754-761.

40. Shimizu S and Tsujimoto $Y(2000)$ Proapoptotic BH3-only Bcl-2 family members induce cytochrome $c$ release, but not mitochondrial membrane potential loss, and do not directly modulate voltage-dependent anion channel activity. Proc. Natl. Acad. Sci. USA 97: 577-582.

41. Ferri KF, Jacotot E, Blanco J, Este JA, Zamzami N, Susin SA, Xie Z, Brothers G, Reed JC, Penninger JM and Kroemer G (2000) Apoptosis control in syncytia induced by the HIV type 1-envelope glycoprotein complex: role of mitochondria and caspases. J. Exp. Med. 192: 1081-1092.

42. Vander Heiden MG, Li XX, Gottleib E, Hill RB, Thompson CB and Colombini M (2001) Bcl-xL promotes the open configuration of the voltage-dependent anion channel and metabolite passage through the outer mitochondrial membrane. J. Biol. Chem. 276: 19414-19419.
43. Vander Heiden MG, Chandel NS, Li XX, Schumacker PT, Colombini M and Thompson CB (2000) Outer mitochondrial membrane permeability can regulate coupled respiration and cell survival. Proc. Natl. Acad. Sci. USA 97: 46664671

44. Cheng EH, Sheiko TV, Fisher JK, Craigen WJ and Korsmeyer SJ (2003) VDAC2 inhibits BAK activation and mitochondrial apoptosis. Science 301: 513517.

45. Stoebner PE, Carayon $\mathrm{P}$, Casellas $\mathrm{P}$, Portier M, Lavabre-Bertrand $\mathrm{T}$, Cuq $\mathrm{P}$ Cano JP, Meynadier J and Meunier L (2001) Transient protection by peripheral benzodiazepine receptors during the early events of ultraviolet light-induced apoptosis. Cell Death Differ. 8: 747-753.

46. Castedo M, Perfettini JL and Kroemer G (2002) Mitochondrial apoptosis and the peripheral benzodiazepine receptor: a novel target for viral and pharmacological manipulation. J. Exp. Med. 196: 1121-1125.

47. Majewski N, Nogueira V, Bhaskar P, Coy PE, Skeen JE, Gottlob K, Chandel NS, Thompson CB, Robey RB and Hay N (2004) Hexokinase-mitochondria interaction mediated by Akt is required to inhibit apoptosis in the presence or absence of Bax and Bak. Mol. Cell 16: 819-830.

48. Rathmell JC, Fox CJ, Plas DR, Hammerman PS, Cinalli RM and Thompson CB (2003) Akt-directed glucose metabolism can prevent Bax conformation change and promote growth factor-independent survival. Mol. Cell. Biol. 23: 7315-7328.

49. Chen $\mathrm{H}$ and Chan $\mathrm{DC}$ (2005) Emerging functions of mammalian mitochondrial fusion and fission. Hum. Mol. Genet. 14 (Spec. no. 2): R283-R289.

50. Perfettini JL, Roumier T and Kroemer G (2005) Mitochondrial fusion and fission in the control of apoptosis. Trends Cell Biol. 15: 179-183.

51. Frank S, Gaume B, Bergmann-Leitner ES, Leitner WW, Robert EG, Catez F, Smith CL and Youle RJ (2001) The role of dynamin-related protein 1, a mediator of mitochondrial fission, in apoptosis. Dev. Cell 1: 515-525.

52. Karbowski M, Lee YJ, Gaume B, Jeong SY, Frank S, Nechushtan A, Santel A, Fuller M, Smith CL and Youle RJ (2002) Spatial and temporal association of Bax with mitochondrial fission sites, Drp1, and Mfn2 during apoptosis. J. Cell Biol. 159: 931-938.

53. Nechushtan A, Smith CL, Lamensdorf I, Yoon SH and Youle RJ (2001) Bax and Bak coalesce into novel mitochondria-associated clusters during apoptosis. J. Cell Biol. 153: 1265-1276.

54. Delivani P, Adrain C, Taylor RC, Duriez PJ and Martin SJ (2006) Role for CED9 and $\mathrm{Egl}-1$ as regulators of mitochondrial fission and fusion dynamics. Mol. Cell 21: 761-773.

55. Cuddeback SM, Yamaguchi H, Komatsu K, Miyashita T, Yamada M, Wu C, Singh S and Wang HG (2001) Molecular cloning and characterization of Bif-1. A novel Src homology 3 domain-containing protein that associates with Bax. J. Biol. Chem. 276: 20559-20565.

56. Karbowski M, Jeong SY and Youle RJ (2004) Endophilin B1 is required for the maintenance of mitochondrial morphology. J. Cell Biol. 166: 1027-1039.

57. Lum MG, Minamikawa T and Nagley P (2002) Microscopic photosensitization: a new tool to investigate the role of mitochondria in cell death. Sci. World J. 2: 1198-1208

58. Finkel E (2001) The mitochondrion: is it central to apoptosis? Science 292: $624-626$.

59. Li P, Nijhawan D, Budihardjo I, Srinivasula SM, Ahmad M, Alnemri ES and Wang X (1997) Cytochrome $c$ and dATP-dependent formation of Apaf-1/ caspase-9 complex initiates an apoptotic protease cascade. Cell 91: 479-489.

60. Lakhani SA, Masud A, Kuida K, Porter Jr GA, Booth CJ, Mehal WZ, Inayat I and Flavell RA (2006) Caspases 3 and 7: key mediators of mitochondrial events of apoptosis. Science 311: 847-851.

61. Finucane DM, Waterhouse NJ, Amarante-Mendes GP, Cotter TG and Green DR (1999) Collapse of the inner mitochondrial transmembrane potential is not required for apoptosis of HL60 cells. Exp. Cell Res. 251: 166-174.

62. Bossy-Wetzel E, Newmeyer DD and Green DR (1998) Mitochondrial cytochrome $c$ release in apoptosis occurs upstream of DEVD-specific caspase activation and independently of mitochondrial transmembrane depolarization. EMBO J. 17: 37-49. 